\title{
Vascular Lumen Formation
}

\author{
Eckhard Lammert and Jennifer Axnick \\ Institute of Metabolic Physiology, Heinrich-Heine-University of Düsseldorf, D-40225 Düsseldorf, Germany \\ Correspondence: lammert@uni-duesseldorf.de
}

The vascular system developed early in evolution. It is required in large multicellular organisms for the transport of nutrients, oxygen, and waste products to and from tissues. The vascular system is composed of hollow tubes, which have a high level of complexity in vertebrates. Vasculogenesis describes the de novo formation of blood vessels, e.g., aorta formation in vertebrate embryogenesis. In contrast, angiogenesis is the formation of blood vessels from preexisting ones, e.g., sprouting of intersomitic blood vessels from the aorta. Importantly, the lumen of all blood vessels in vertebrates is lined and formed by endothelial cells. In both vasculogenesis and angiogenesis, lumen formation takes place in a cord of endothelial cells. It involves a complex molecular mechanism composed of endothelial cell repulsion at the cell-cell contacts within the endothelial cell cords, junctional rearrangement, and endothelial cell shape change. As the vascular system also participates in the course of many diseases, such as cancer, stroke, and myocardial infarction, it is important to understand and make use of the molecular mechanisms of blood vessel formation to better understand and manipulate the pathomechanisms involved.

\begin{abstract}
All large multicellular organisms require a Avasculature for the supply of tissues with nutrients and oxygen, and for the removal of metabolic waste products and carbon dioxide from tissues. Thus, the cardiovascular system developed early during evolution of large multicellular organisms. Importantly, diffusion of oxygen is only possible within a reasonable time over few cell diameters to ensure proper tissue oxygenation. In addition, the solubility of oxygen in aqueous solutions, such as interstitial fluid or cell plasma, is low. Thus, a cardiovascular system that pumps oxygen carrier proteins close to the cells of all tissues is needed for aerobic metabolism and thus for development, growth, and homeostasis. A common feature of most cardiovascular systems found in
\end{abstract}

the animal kingdom is the presence of contracting muscular structures, which serve as pumps to circulate blood through multicellular tubes or channels within the entire organism (Fig. 1).

\section{Morphology and Formation of Invertebrate Blood Vessels}

Invertebrates have various different vascular systems. Porifera and Cnidaria, for example, have a body cavity with apical cilia that serves both for nutrient and oxygen uptake, and therefore, it is sometimes called the gastrovascular cavity. Arthropodes and mollusks (but not cephalopods) have an open circulatory system (Fig. 1A), in which the cardiovascular system is separated from the gastrointestinal system. It

Editors: Michael Klagsbrun and Patricia D'Amore

Additional Perspectives on Angiogenesis available at www.perspectivesinmedicine.org

Copyright (C) 2012 Cold Spring Harbor Laboratory Press; all rights reserved; doi: 10.1101/cshperspect.a006619

Cite this article as Cold Spring Harb Perspect Med 2012;2:a006619 
A

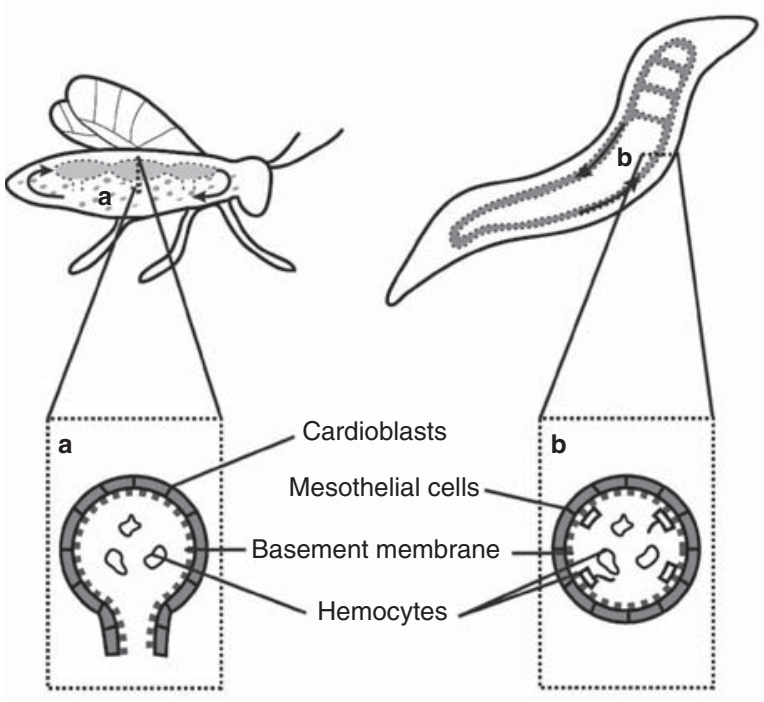

Invertebrates
B
Closed circulatory system: (without endothelium)
C

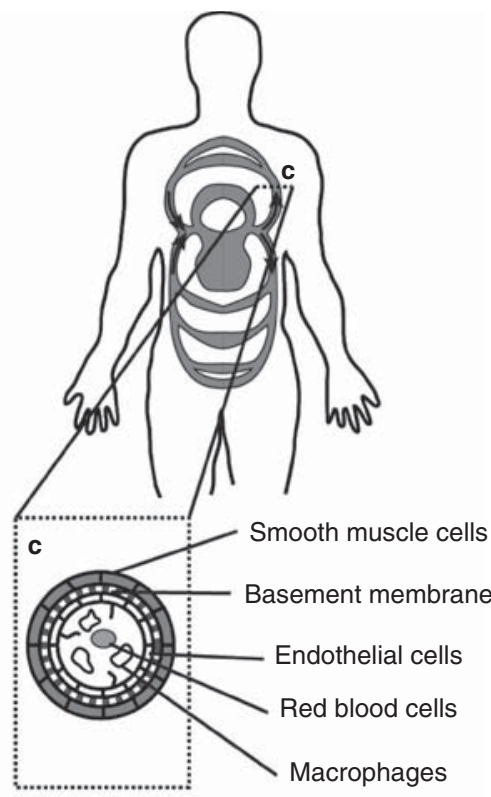

Vertebrates

Closed circulatory system: (endothelium-lined)

Mammals Amphibians

Reptiles

Figure 1. Circulatory systems in multicellular organisms. Schematic drawings of representative multicellular organisms. Black dotted lines indicate the place of cross sections shown in the boxes below $(\mathrm{a}-\mathrm{c})$. $(A)$ In arthropods and mollusks the organs are surrounded by hemolymph. The heart pumps the hemolymph into the open hemocoel from where it is retrieved back into the heart (arrows). (a) The vascular system is lined with a layer of cardioblasts and a luminal basement membrane. The hemolymph contains hemocytes. $(B)$ In annelids, cephalopods, holothurians, and amphioxus the blood is located in a closed vascular system. The latter consists of blood vessels in which the blood is pumped by contractile myoepithelial cells (arrows show the direction of the blood flow). (b) The vessels are lined by the basement membrane of mesothelial cells and/or intestinal cells. Hemocytes occur free in the vessel lumen as well as adherent at the luminal basement membrane. $(C)$ In vertebrates, the circulatory system is closed. The blood is pumped through the whole organism by the heart. Arrows indicate the direction of blood flow. (c) The vasculature is lined by the apical cell surface of endothelial cells. In contrast, the vascular basement membrane is abluminally located. Peripheral mural cells are located basal, within or at the basement membrane, and stabilize the vessels. The blood mainly contains red blood cells, besides leukocytes and thrombocytes. (Figure is from Strilic et al. 2010; reprinted, with permission, from Springer (C) 2010.)

is closed toward the outside, but opened toward the coelom and interstitium. The cardiovascular lumen is surrounded by the basal cell surface of cardioblasts (Yarnitzky and Volk 1995). Hemolymph is the name of the blood fluid, which is pumped from the heart to the open hemocoel and back to the heart. Cephalopods (Barber and Graziadei 1965), annelids (Graupera et al. 2008), holothurians (Herreid et al. 1976), and amphioxus (Ruppert 1997) have a 
Vascular Lumen Formation

closed circulatory system (Fig. 1B), composed of simple channels lined by a basal cell surface of mesothelial or intestinal cells, extracellular matrix, and/or basement membrane. The lumen contains plasma and blood cells, called hemocytes (Haag et al. 1999).

\section{Formation of Invertebrate Blood Vessels}

Different mechanisms regulate vascular lumen formation in invertebrates. In amphioxus, for example, a laminin-containing extracellular matrix (ECM) separates the basal cell surface of endoderm and mesoderm from each other along the anterior-posterior axis (Stach 1998; Kucera et al. 2009). In this ECM-filled extracellular space, hemocytes are present, which are involved in depositing, degrading, and adhering to the basal ECM (Kucera et al. 2009). Hemocytes are often found both adherent to the basement membrane and located within the developing vascular lumen (Fig. 1B) (Adachi et al. 2005; Fessler and Fessler 1989).

In the annelid Sabellaria cementarium, the blood vessels are likely to form through separation of apposing basement membranes, which are present on the basal cell surfaces of mesothelial cell sheets (Graupera et al. 2008). During deadhesion of these cell sheets, blood appears between the two separating mesothelial cell layers, and thus the lumen may develop by repulsion of apposing basal cell surfaces.

During heart formation in Drosophila melanogaster, cardioblasts develop from the lateral plate mesoderm, migrate toward the midline, and form a heart tube (Rugendorff et al. 1994), a process regulated by the Robo-Slit pathway (Qian et al. 2005; MacMullin and Jacobs 2006; Santiago-Martinez et al. 2006). During this process, basal cell surfaces (connection via Drosophila epithelial [DE] cadherin) most likely deadhere from each other or wrap around to form the developing cardiovascular lumen (Haag et al. 1999; Medioni et al. 2008; Santiago-Martinez et al. 2008).

Taking these organisms as examples, many or most invertebrates form a cardiovascular lumen by using their basal cell surfaces (Fig. 1A,B).

\section{Morphology of Vertebrate Blood Vessels}

Vertebrates have a closed circulatory system lined by endothelial cells (ECs) (Fig. 1C). The blood mainly contains red blood cells, besides leukocytes and thrombocytes (Fig. 1C). Vertebrate blood vessels are composed of an endothelial cell layer facing the vascular lumen with its apical cell surface. A basement membrane and mural cells (smooth muscle cells or pericytes) are positioned abluminally on the outside of the endothelial cell tube (Betsholtz et al. 2005; C). The vertebrate vascular system is a complex system of different types of blood vessels (Eichmann et al. 2005; Yano et al. 2007). Arteries transport the blood away from the heart and are surrounded by a tight layer of mural cells. Veins conduct the blood back to the heart and contain venous valves, which develop from an invagination of the endothelial cell layer with its basement membrane and prevent a backflow of the blood. Generally, veins harbor less mural cells on their outside. Capillaries connect the small arteries, called arterioles, with small veins, called venules. Delivery of nutrients and oxygen, as well as removal of waste products and carbon dioxide, takes place in capillaries. Capillaries are 5-10 $\mu \mathrm{m}$ in diameter and contain pericytes on their abluminal side. In contrast, large vertebrate blood vessels contain three principal tissue layers: the tunica intima composed of ECs, the tunica media composed of smooth muscle cells, nerve cells, and extracellular elastin, and the tunica externa composed of collagen fibers and fibroblasts.

All vertebrates harbor an endotheliumlined vascular system, suggesting a selective advantage of this kind of system over the vascular system of invertebrates (Kucera et al. 2009). Possible advantages of endothelium-lined blood vessels could be that vessels with ECs are modular and are able to change their morphology according to the needs of the surrounding tissues. Furthermore, EC-lined blood vessels form defined routes, which can be opened and closed via the surrounding mural cells to adapt to the metabolic needs and physiologic requirements of the entire organism. Another advantage could be that the apical EC 
surfaces form a smooth cell surface with the help of their apical glycocalyx (Strilic et al. 2010a), lowering the resistance for blood flow, and thus enabling fast blood flow to and from tissues. ECs can also become prothrombotic, in case of injury, and are able to attract immune cells to sites of tissue injury.

\section{Vertebrate Blood Vessel Formation}

Two different ways of blood vessel formation occur in vertebrates: angiogenesis and vasculogenesis (Fong et al. 1999; Olsson et al. 2006; Adams and Alitalo 2007). A third mode has been described for the formation of the cardinal vein (Herbert et al. 2009). Angiogenesis describes blood vessel formation from preexisting vessels, e.g., via blood vessel sprouting (Walls et al. 2008; Lawson and Weinstein 2002). Vasculogenesis is the process of forming a blood vessel de novo in the absence of preexisting vessels (Parker et al. 2004; Strilic et al. 2009). In general, vertebrate blood vessel formation consists of three basic steps: (1) formation of a multicellular endothelial cell cord, (2) formation of a central vascular lumen within this cord, and (3) initiation of blood flow through the vascular lumen (Fig. 1C) (Kamei et al. 2006; Blum et al. 2008; Herbert et al. 2009; Strilic et al. 2009). The first blood vessel to develop de novo in mammals is the dorsal aorta (Fong et al. 1999), and the aorta develops into the largest arterial blood vessel. In mammalian embryonic development, ECs form two dorsal aortas simultaneously on both sides of the neural tube, and fuse in the midline during later embryonic development.

\section{MOLECULAR STEPS OF VASCULAR LUMEN FORMATION IN MAMMALS}

During embryonic development, ECs first start to differentiate from angioblasts (EC precursor) and start to express EC markers, such as platelet and endothelial cell adhesion molecule-1 (PECAM-1) and vascular endothelial growth factor receptor-2 (VEGFR-2). These ECs migrate toward the endoderm guided by VEGF to form the aortic primordia. In a transversal cross section of the mouse dorsal aorta, two to three ECs are often found next to each other (Fig. 2A).

\section{Cell-Cell Junctions in ECs}

Vascular endothelial cadherin (VE-cadherin) is a cell adhesion molecule belonging to the cadherin protein family and is exclusively expressed in ECs and some tumor cells (Cavallaro et al. 2006; Labelle et al. 2008). VE-cadherin facilitates homotypic interactions between ECs, but is not strictly required for the adhesion of ECs to each other. Another cell adhesion molecule expressed in ECs is the neural cadherin (N-cadherin) (Luo and Radice 2005), which seems to increase the amount of VE-cadherin at the endothelial cell-cell contact. In contrast, VE-cadherin is strictly required for the polarization of ECs in vitro and in vivo (Strilic et al. 2009; Lampugnani et al. 2010). VE-cadherin and adherens junctions are initially located throughout the entire endothelial cell-cell contact in a punctuated manner before they localize to lateral positions (Fig. 2A,B).

\section{EC Polarity}

In epithelial and endothelial cells, it has been shown that polarization often starts with the delivery of deadhesive apical glycoproteins to the cell-cell contact via exocytosis (MartinBelmonte et al. 2007; Ferrari et al. 2008). Deadhesive molecules include CD34-sialomucins, such as CD34 and podocalyxin (PODXL) (Fig. 2B). During delivery of apical glycoproteins to the cell-cell contact, the adherens junctions translocate to lateral positions (Fig. 2B). Two possibilities are suspected to be involved in this junctional rearrangement: Either VEcadherin is endocytosed at the cell-cell contact or VE-cadherin is pushed to the lateral cell borders by apical glycoproteins. The new junctions have properties of adherens (AJ) and tight junctions (TJ), as they contain both VE-cadherin (characteristic of AJ) and ZO-1 protein (characteristic of TJ) (Bazzoni and Dejana 2004). At the time when apical glycoproteins are delivered to the cell-cell contact, F-actin gets recruited to 


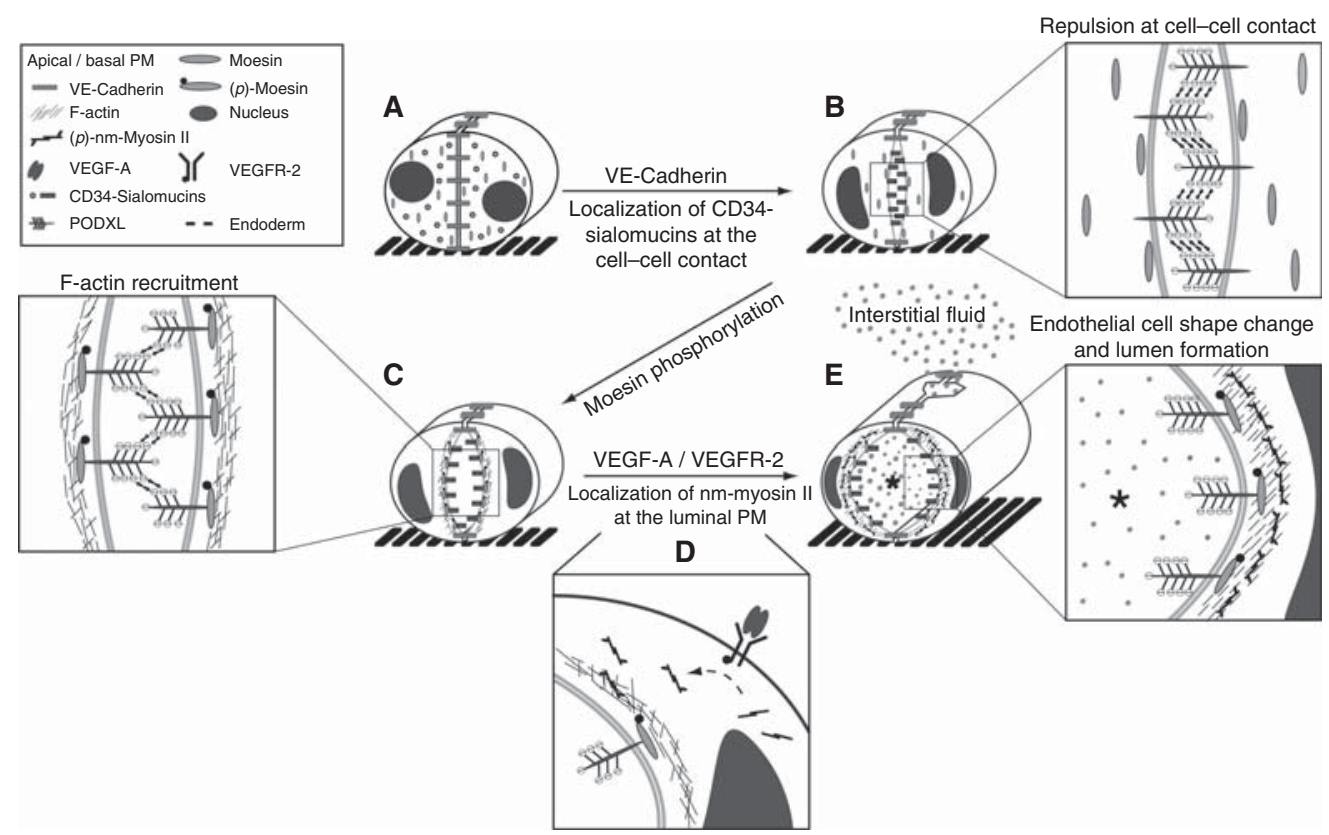

Figure 2. Molecular mechanism of de novo lumen formation. Schematic drawings of a developing aorta. $(A)$ A part of an endothelial cell cord is shown. ECs are connected via adherens junctions (most prominently vascular endothelial [VE]-cadherin) along the entire endothelial cell-cell contact. The sialomucin PODXL is localized in vesicles. (B) VE-cadherin is involved in localizing negatively charged PODXL to the endothelial cell-cell contact. VE-cadherin itself is translocated to the lateral cell areas. Vesicles with PODXL are released at the cell-cell contact to form an apical cell surface, and the negatively charged sialic acids of PODXL and the other apical glycoproteins lead to a repulsion (arrows) of the apical cell surfaces. This results in the formation of a small slit from which the lumen subsequently develops. $(C)$ After its phosphorylation, moesin and other Ezrin-Radixin-Moesin (ERM) proteins connect PODXL to the F-actin cytoskeleton. (D) VEGF-A activates VEGFR-2, which leads to the phosphorylation of nonmuscular ( $\mathrm{nm}$ ) myosin II and formation of actomyosin complexes. (E) The F-actin cytoskeleton and actomyosin generate the force needed to further separate the apposing apical cell surfaces and thus widen the aortic lumen. (Figure is from Strilic et al. 2009; reprinted, with permission, from Elsevier (C) 2009.)

the apical cell surface. Electrostatic repulsion of apposing cell surfaces, owing to the negatively charged apical glycocalyx (Fig. 2B, arrows), leads to the development of small slits between the adjacent ECs (Strilic et al. 2010a), which subsequently expand in lumen width. Similar to the apical glycoproteins, VE-cadherin also gets connected to the F-actin cytoskeleton in ECs.

\section{Intracellular Steps}

ERM proteins (ezrin, radixin, and moesin) are recruited to the apical EC surface (Strilic et al. 2009) and get phosphorylated via protein kinase $\mathrm{C}$ (PKC). Moesin is the most abundant ERM protein in ECs (Nielsen and McNagny
2008). However, other ERM proteins, i.e., ezrin and radixin, are also found in ECs, suggesting functional redundancy. Moesin can bind directly or via adaptors to the cytoplasmic domains of apical glycoproteins, such as PODXL (Fig. 2C). Thus, phosphorylated ERM proteins can directly link the apical glycoproteins to F-actin in ECs (Fig. 2C).

\section{VEGFR-2 Signaling}

Formation of apical cell surfaces and electrostatic repulsion are sufficient for the initial deadhesion of adjacent ECs and for slit formation, but are not sufficient for the development of a patent vascular lumen. Vascular endothelial 
growth factor-A (VEGF-A) therefore induces cell shape changes that further separate the apical cell surfaces from each other (Strilic et al. 2009). A VEGF-A dimer binds to its receptor VEGFR-2 (Fig. 2D), which dimerizes and transphosphorylates itself on tyrosine residues. Downstream from VEGFR-2 Rho-associated protein kinase (ROCK) gets activated, which subsequently stimulates formation of an actomyosin complex. With regard to nonmuscular myosin II light chain (nm-MLC), the phosphorylation of nm-MLC increases (Sun et al. 2006), which allows nm-myosin II to interact with the F-actin cytoskeleton (Fig. 2D). The F-actin cytoskeleton and actomyosin complexes subsequently generate the force needed to further separate the apposing apical cell surfaces and thus widen the aortic lumen (Fig. 2E).

\section{MORPHOLOGICAL CHANGES DURING VASCULAR LUMEN FORMATION}

Two different ways of lumen formation have been discussed: cord hollowing (Billroth 1856) and cell hollowing (Sabin 1920). Cell hollowing was suggested to be a mechanism of vascular lumen formation (Folkman and Haudenschild 1980; Davis and Camarillo 1996; Kamei et al.
2006). According to the vacuole coalescence model, ECs form large intracellular vacuoles, which constitute a central vascular lumen inside each EC, thus giving rise to a seamless vascular lumen. In addition, the vacuoles arise from pinocytosis, as shown by in vitro studies (Davis and Camarillo 1996). Newer studies, however, showed that cord hollowing is more likely to be the common mechanism of vascular lumen formation in the majority of blood vessels (Parker et al. 2004; Jin et al. 2005; Blum et al. 2008; Herbert et al. 2009; Strilic et al. 2009).

During the VEGF-driven cytoskeletal events, the apposing apical endothelial cell surfaces separate from each other. Simultaneously, the ECs and also their nuclei elongate in parallel to the developing lumen and flatten (Fig. 2C-E).

\section{Junctional Remodeling during Lumen Formation}

Vascular lumen formation is a dynamic process (Parker et al. 2004; Jin et al. 2005; Blum et al. 2008; Strilic et al. 2009). After a lumen has formed within an endothelial cell cord, junctional remodeling can take place (Fig. 3) (Strilic et al. 2010b). It was shown in the development of tracheae in D. melanogaster that multicellular

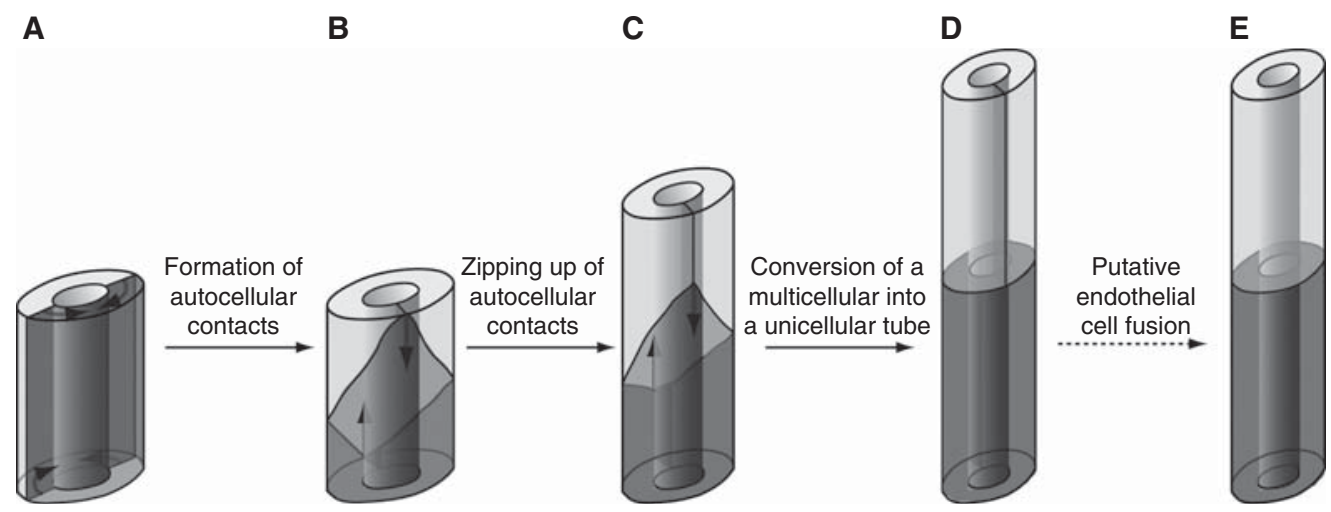

Figure 3. Transition of multicellular blood vessels into unicellular and seamless blood vessels. (A) A multicellular tube (consisting of a light cell and a dark cell) has a central lumen joined by lateral junctions. The cells reach around the lumen (arrows) to form autocellular cell-cell contacts. $(B)$ When the junctions meet at the opposite sides of the lumen, they start zipping up in two directions (arrows). (C) Autocellular contacts therefore replace the intercellular cell-cell contacts. $(D)$ The conversion of a multicellular tube into a unicellular tube is completed. (E) Conversion of a unicellular into a seamless vascular tube via fusion of the plasma membrane at the autocellular contact sites. (Figure is from Strilic et al. 2010b; reprinted, with permission, from Springer (C) 2010.) 
tubes are able to rearrange their junctions and thereby form unicellular tubes from multicellular ones (Fig. 3A-D) (Ribeiro et al. 2004). Because ECs have fusogenic functions, it is also possible that an EC fuses with itself to form a seamless blood vessel (Fig. 3D,E). Indeed, capillaries can have only one or even no junction on cross sections, supporting the notion that junctions can significantly rearrange after lumen formation by cord hollowing.

\section{Lumen Expansion}

The lumen diameter of vessels must increase during the entire embryonic and juvenile development. The aorta lumen increases from $5 \mu \mathrm{m}$ (Strilic et al. 2009) to 1 in in humans. During early embryogenesis despite lack of blood flow and mural cell coverage (Strilic et al. 2009; Wiegreffe et al. 2009), EC proliferation directly affects lumen diameter (Graupera et al. 2008; Stenman et al. 2008). In the adult, hemodynamic stimuli caused by shear stress significantly contribute to increased lumen diameter. During stenosis of blood vessels, collateral blood vessels (in particular, arterioles) significantly expand their lumen diameter to compensate for the narrowing of a large coronary artery (Cai and Schaper 2008).

\section{MEDICAL APPLICATIONS}

The endothelium is involved in most human diseases. Thus it is necessary to learn more about vascular lumen formation on a molecular level for better understanding the pathomechanisms of diseases and for designing new drugs or therapies.

\section{Cancer and Metastasis}

In malignant tumors, blood supply helps the tumor to quickly grow and compete with healthy tissue for space, nutrition, and oxygenation. The characteristics of malignant tumors are the fast-growing, invasive cells, which break the tissue borders to form metastasis. To get access to nutrients and oxygen, tumors can receive blood supply via angiogenesis and/or vasculogenesis. However, in some malignant tumors, tubular structures, probably formed by the tumor cells themselves, are found. It has been suggested that the tumor cells can form vessels to enable supply with oxygen and nutrients, a process called "vascular mimicry" (Maniotis et al. 1999). Like in invertebrates, the lumen of these channels is lined by basement membrane (Kucera and Lammert 2009). These channels are supposed to transport plasma to the tumor tissue (Maniotis et al. 1999). Vascular mimicry-derived channels vary in size, and therefore, it is difficult to imagine a normal red blood cell circulation in these tumors. However, because blood cells can rupture in uneven tumor blood vessels, it is possible to speculate that extraerythrocytic hemoglobin contributes to the oxygenation of the tumors to some extent (Bürgers and Lammert 2011), similar to the situation found in the earthworm. Thus, understanding the molecular mechanisms of neovascularization via ECs and vascularization via vasculogenic mimicry is critical for better designing antitumor drugs.

\section{Common Stenoses}

Arteriogenesis is caused by an increased fluid shear stress, which is caused by a higher blood flow through the small collateral arteries when the major arteries become occluded (Cai and Schaper 2008). In response to an increased shear stress, ECs start expression of chemoattractant molecules and growth factors, which make ECs and smooth muscle cells (SMCs) proliferate, thus resulting in the expansion of an arteriole to a larger artery. Again, a better understanding of the underlying molecular mechanisms is required for stimulating the arteriogenic process in patients suffering from stenosis to prevent infarction, such as myocardial infarction.

\section{OUTLOOK}

Until recently, the molecular and cellular mechanisms involved in blood vessel lumen formation have been largely unknown. However, the analyses of the dorsal aortae in mouse embryos 
and intersomitic vessels in zebrafish embryos set an experimental framework for dissecting the molecular mechanisms involved in blood vessel lumen formation and expansion. This framework will help to put various molecules involved in blood vessel lumen formation and lumen widening into a mechanistic model to define their functional roles (Figs. 2 and 3 ).

\section{REFERENCES}

Adachi T, Tomita M, Yoshizato K. 2005. Synthesis of prolyl 4-hydroxylase $\alpha$ a subunit and type IV collagen in hemocytic granular cells of silkworm, Bombyx mori: Involvement of type IV collagen in self-defense reaction and metamorphosis. Matrix Biol 24: 136-154.

Adams RH, Alitalo K. 2007. Molecular regulation of angiogenesis and lymphangiogenesis. Nat Rev Mol Cell Biol 8: 464-478.

Barber VC, Graziadei P. 1965. The fine structure of cephalopod blood vessels. I. Some smaller peripheral vessels. Z Zellforsch Mikrosk Anat 66: 765-781.

Bazzoni G, Dejana E. 2004. Endothelial cell-to-cell junctions: Molecular organization and role in vascular homeostasis. Physiol Rev 84: 869-901.

Betsholtz C, Lindblom P, Gerhardt H. 2005. Role of pericytes in vascular morphogenesis. EXS 115-125.

Billroth T. 1856. Untersuchungen über die Entwicklung der Blutgefässe, nebst Beobachtungen aus der königlichen chirurigischen Universitäts-Klinik zu Berlin. Georg Reimer, Berlin.

Blum Y, Belting HG, Ellertsdottir E, Herwig L, Luders F, Affolter M. 2008. Complex cell rearrangements during intersegmental vessel sprouting and vessel fusion in the zebrafish embryo. Dev Biol 316: 312-322.

Bürgers AC, Lammert E. 2011. Extraerythrocytic hemoglobin-A possible oxygen transporter in human malignant tumors. Med. Hypotheses 77: 580-583.

Cai W, Schaper W. 2008. Mechanisms of arteriogenesis. Acto Biochim Biophys Sin 40: 681-692.

Cavallaro U, Liebner S, Dejana E. 2006. Endothelial cadherins and tumor angiogenesis. Exp Cell Res 312: 659-667.

Davis GE, Camarillo CW. 1996. An $\alpha 2 \beta 1$ integrin-dependent pinocytic mechanism involving intracellular vacuole formation and coalescence regulates capillary lumen and tube formation in three-dimensional collagen matrix. Exp Cell Res 224: 39-51.

Eichmann A, Yuan L, Moyon D, Lenoble F, Pardanaud L, Breant C. 2005. Vascular development: From precursor cells to branched arterial and venous networks. Int $J$ Dev Biol 49: 259-267.

Ferrari A, Veligodskiy A, Berge U, Lucas MS, Kroschewski R. 2008. ROCK-mediated contractility, tight junctions and channels contribute to the conversion of a preapical patch into apical surface during isochoric lumen initiation. J Cell Sci 121: 3649-3663.

Fessler JH, Fessler LI. 1989. Drosophila extracellular matrix. Annu Rev Cell Biol 5: 309-339.
Folkman J, Haudenschild C. 1980. Angiogenesis in vitro. Nature 288: 551-556.

Fong TA, Shawver LK, Sun L, Tang C, App H, Powell TJ, Kim YH, Schreck R, Wang X, Risau W, et al. 1999. SU5416 is a potent and selective inhibitor of the vascular endothelial growth factor receptor (Flk-1/KDR) that inhibits tyrosine kinase catalysis, tumor vascularization, and growth of multiple tumor types. Cancer Res 59: 99-106.

Graupera M, Guillermet-Guibert J, Foukas LC, Phng LK, Cain RJ, Salpekar A, Pearce W, Meek S, Millan J, Cutillas $\mathrm{PR}$, et al. 2008. Angiogenesis selectively requires the pp110 $\alpha$ isoform of PI3K to control endothelial cell migration. Nature 453: 662-666.

Haag TA, Haag NP, Lekven AC, Hartenstein V. 1999. The role of cell adhesion molecules in Drosophila heart morphogenesis: Faint sausage, shotgun/DE-cadherin, and laminin $A$ are required for discrete stages in heart development. Dev Biol 208: 56-69.

Herbert SP, Huisken J, Kim TN, Feldman ME, Houseman BT, Wang RA, Shokat KM, Stainier DY. 2009. Arterialvenous segregation by selective cell sprouting: An alternative mode of blood vessel formation. Science 326: 294 298.

Herreid CF, Larussa VF, Defesi CR. 1976. Blood vascular system of sea-cucumber, stichopus-moebii. J Morphol 150: 423-451.

Jin SW, Beis D, Mitchell T, Chen JN, Stainier DY. 2005. Cellular and molecular analyses of vascular tube and lumen formation in zebrafish. Development 132: 5199-5209.

Kamei M, Saunders WB, Bayless KJ, Dye L, Davis GE, Weinstein BM. 2006. Endothelial tubes assemble from intracellular vacuoles in vivo. Nature 442: 453-456.

Kucera T, Lammert E. 2009. Ancestral vascular tube formation and its adoption by tumors. Biol Chem 390: 985994.

Kucera T, Strilic B, Regener K, Schubert M, Laudet V, Lammert E. 2009. Ancestral vascular lumen formation via basal cell surfaces. PLoS One 4: e4132. doi: 10.1371/ journal.pone.0004132.

Labelle M, Schnittler HJ, Aust DE, Friedrich K, Baretton G, Vestweber D, Breier G. 2008. Vascular endothelial cadherin promotes breast cancer progression via transforming growth factor beta signaling. Cancer Res 68: 1388-1397.

Lampugnani MG, Orsenigo F, Rudini N, Maddaluno L, Boulday G, Chapon F, Dejana E. 2010. CCM1 regulates vascular-lumen organization by inducing endothelial polarity. J Cell Sci 123: 1073-1080.

Lawson ND, Weinstein BM. 2002. In vivo imaging of embryonic vascular development using transgenic zebrafish. Dev Biol 248: 307-318.

Luo Y, Radice GL. 2005. N-cadherin acts upstream of VE-cadherin in controlling vascular morphogenesis. $J$ Cell Biol 169: 29-34.

MacMullin A, Jacobs JR. 2006. Slit coordinates cardiac morphogenesis in Drosophila. Dev Biol 293: 154-164.

Maniotis AJ, Folberg R, Hess A, Seftor EA, Gardner LM, Pe'er J, Trent JM, Meltzer PS, Hendrix MJ. 1999. Vascular channel formation by human melanoma cells in vivo and in vitro: Vasculogenic mimicry. Am J Pathol 155: 739-752. 
Martin-Belmonte F, Gassama A, Datta A, Yu W, Rescher U, Gerke V, Mostov K. 2007. PTEN-mediated apical segregation of phosphoinositides controls epithelial morphogenesis through Cdc42. Cell 128: 383-397.

Medioni C, Astier M, Zmojdzian M, Jagla K, Semeriva M 2008. Genetic control of cell morphogenesis during Drosophila melanogaster cardiac tube formation. J Cell Biol 182: $249-261$.

Nielsen JS, McNagny KM. 2008. Novel functions of the CD34 family. J Cell Sci 121: 3683-3692.

Olsson AK, Dimberg A, Kreuger J, Claesson-Welsh L. 2006. VEGF receptor signalling - In control of vascular function. Nat Rev Mol Cell Biol 7: 359-371.

Parker LH, Schmidt M, Jin SW, Gray AM, Beis D, Pham T Frantz G, Palmieri S, Hillan K, Stainier DY, et al. 2004. The endothelial-cell-derived secreted factor Egfl7 regulates vascular tube formation. Nature 428: 754-758.

Qian L, Liu J, Bodmer R. 2005. Slit and Robo control cardiac cell polarity and morphogenesis. Curr Biol 15: 22712278.

Ribeiro C, Neumann M, Affolter M. 2004. Genetic control of cell intercalation during tracheal morphogenesis in Drosophila. Curr Biol 14: 2197-2207.

Rugendorff A, Younossihartenstein A, Hartenstein V. 1994 Embryonic origin and differentiation of the Drosophila heart. Rouxs Arch Dev Biol 203: 266-280.

Ruppert E. 1997. Cephalochordata (Acrania). In Microscopic anatomy of invertebrates (ed. Harrison FW). Wiley-Liss, Wilmington.

Sabin F. 1920. Studies on the origin of blood-vessels and of red-corpuscles as seen in the living blastoderm of chicks during the second day of incubation. Contrib Embryol 9: 213-262.

Santiago-Martinez E, Soplop NH, Kramer SG. 2006. Lateral positioning at the dorsal midline: Slit and Roundabout receptors guide Drosophila heart cell migration. Proc Natl Acad Sci 103: 12441-12446.

Santiago-Martinez E, Soplop NH, Patel R, Kramer SG. 2008. Repulsion by Slit and Roundabout prevents Shotgun E-cadherin-mediated cell adhesion during Drosophila heart tube lumen formation. J Cell Biol 182: 241-248.
Stach T. 1998. Coelomic cavities may function as a vascular system in amphioxus larvae. Biol Bull 195: 260-263.

Stenman JM, Rajagopal J, Carroll TJ, Ishibashi M, McMahon J, McMahon AP. 2008. Canonical Wnt signaling regulates organ-specific assembly and differentiation of CNS vasculature. Science 322: 1247-1250.

Stenzel D, Nye E, Nisancioglu M, Adams RH, Yamaguchi Y, Gerhardt H. 2009. Peripheral mural cell recruitment requires cell-autonomous heparan sulfate. Blood 114: 915-924.

Strilic B, Kucera T, Eglinger J, Hughes MR, McNagny KM, Tsukita S, Dejana E, Ferrara N, Lammert E. 2009. The molecular basis of vascular lumen formation in the developing mouse aorta. Dev Cell 17: 505-515.

Strilic B, Eglinger J, Krieg M, Zeeb M, Axnick J, Babal P, Müller DJ, Lammert E. 2010a. Electrostatic cell-surface repulsion initiates lumen formation in developing blood vessels. Curr Biol 20: 2003-2009.

Strilic B, Kucera T, Lammert E. 2010b. Formation of cardiovascular tubes in invertebrates and vertebrates. Cell $\mathrm{Mol}$ Life Sci 67: 3209-3218.

Sun H, Breslin JW, Zhu J, Yuan SY, Wu MH. 2006. Rho and ROCK signaling in VEGF-induced microvascular endothelial hyperpermeability. Microcirculation 13: 237-247.

Walls JR, Coultas L, Rossant J, Henkelman RM. 2008. Threedimensional analysis of vascular development in the mouse embryo. PLoS One 3: e2853. doi: 10.1371/ journal.pone.0002853.

Wiegreffe C, Christ B, Huang R, Scaal M. 2009. Remodeling of aortic smooth muscle during avian embryonic development. Dev Dyn 238: 624-631.

Yano K, Gale D, Massberg S, Cheruvu PK, Monahan-Earley R, Morgan ES, Haig D, von Andrian UH, Dvorak AM, Aird WC. 2007. Phenotypic heterogeneity is an evolutionarily conserved feature of the endothelium. Blood 109: 613-615.

Yarnitzky T, Volk T. 1995. Laminin is required for heart, somatic muscles, and gut development in the Drosophila embryo. Dev Biol 169: 609-618. 


\title{
$\&_{\mathrm{CSH}}^{\infty} \&$ Cold Spring Harbor

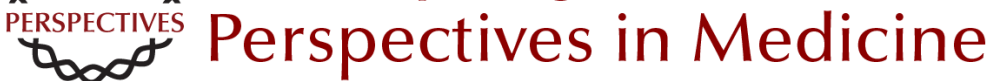

\section{Vascular Lumen Formation}

\author{
Eckhard Lammert and Jennifer Axnick
}

Cold Spring Harb Perspect Med 2012; doi: 10.1101/cshperspect.a006619 originally published online October 25, 2011

\section{Subject Collection Angiogenesis}

Extracellular Matrix Regulation of Vascular Morphogenesis, Maturation, and Stabilization George E. Davis and Scott S. Kemp

Endothelial Cell-Pericyte Interactions in the Pathogenesis of Cerebral Cavernous Malformations (CCMs) Wang Min and Jenny Huanjiao Zhou

Lymphatic Clearance and Pump Function Jerome W. Breslin

Platelets and (Lymph)angiogenesis Harvey G. Roweth and Elisabeth M. Battinelli

Modeling Brain Vasculature Immune Interactions In Vitro Ruth Lyck, Hideaki Nishihara, Sidar Aydin, et al.

Human Endothelial Colony-Forming Cells Juan M. Melero-Martin

\section{The Beauty and Complexity of Blood Vessel Patterning Victoria L. Bautch and Yoh-suke Mukouyama \\ Endothelialitis, Microischemia, and Intussusceptive Angiogenesis in COVID-19 Steven J. Mentzer, Maximilian Ackermann and Danny Jonigk}

\author{
Regulation of the Blood-Brain Barrier in Health \\ and Disease \\ Cara C. Rada, Kanako Yuki, Jie Ding, et al. \\ Targeting Angiogenesis via Resolution of \\ Inflammation \\ Abigail G. Kelly and Dipak Panigrahy
}

Notch Signaling in the Vasculature: Angiogenesis and Angiocrine Functions

Sana S. Hasan and Andreas Fischer

Signal Transduction and Gene Regulation in the

Endothelium

Michel V. Levesque and Timothy Hla

Buttons and Zippers: Endothelial Junctions in

Lymphatic Vessels

Peter Baluk and Donald M. McDonald

Endothelial Cell Fate Determination: A Top Notch Job in Vascular Decision-Making

L.A. Naiche, Stephanie R. Villa and Jan K. Kitajewski

Leukocyte Trafficking in Lymphatic Vessels Aline Bauer, Hazal Tatliadim and Cornelia Halin

Lymphatic Tissue and Organ Engineering for In Vitro Modeling and In Vivo Regeneration Anna M. Kolarzyk, Gigi Wong and Esak Lee

For additional articles in this collection, see http://perspectivesinmedicine.cshlp.org/cgi/collection/ 